\title{
SOME PLANT GROWTH PROMOTING TRAITS OF STREPTOMYCES SPECIES ISOLATED FROM VARIOUS CROP RHIZOSPHERES WITH HIGH ROOT COLONIZATION ABILITY OF SPINACH (SPINACIA OLERACEA L.)
}

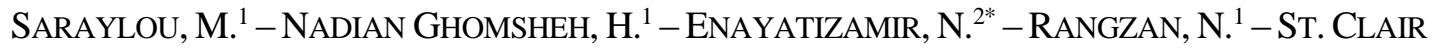 \\ SENN, S. $^{3}$ \\ ${ }^{I}$ Department of Soil Science and Engineering, Faculty of Agriculture, Agricultural Science and \\ Natural Resources University of Khuzestan, Mollasani, Iran \\ (e-mail: Maryam.sarayloo64@yahoo.com,Nadian_habib@yahoo.com,nafas023@yahoo.com) \\ ${ }^{2}$ Department of Soil Science and Engineering, Faculty of Agriculture, Shahid Chamran \\ University of Ahvaz, Ahvaz, Iran \\ ${ }^{3}$ Agriculture Sciences Department, Pierce College, Los Angeles, CA, USA \\ (e-mail: stclais@piercecollege.edu) \\ *Corresponding author \\ e-mail:n.enayatzamir@scu.ac.ir \\ (Received $7^{\text {th }}$ Feb 2021; accepted $14^{\text {th }}$ May 2021)
}

\begin{abstract}
Streptomyces species a genus in Actinobacteria phylum were isolated from the rhizosphere of some plants in Los Angeles. Some plant growth promotion properties of isolates were determined, such as: indole acetic acid, siderophore production and phosphate solubilization. The colonization ability of Streptomyces species was investigated under in vitro conditions on spinach seeds. Maximum likelihood approach was applied to 16S rRNA gene sequences to draw a phylogenetic tree of the best identified isolates, according to their measured properties. A total of ten isolates were characterized as Actinobacteria according to their morphological properties. Of those, four isolates possessing some traits related to plant growth promotion were identified as Streptomyces griseus strain 52-1 (Step1) and Streptomyces albogriseolus strain DSM 4 (Step-2) from tomatoes, Streptomyces aurantiacus strain 4683 (Step-5) and Streptomyces kanamyceticus strain 22-5 (Step-8) from sunflowers' rhizosphere. The identified isolates showed the maximum indole acetic acid production, 95.67, 110.14, 94.12 and 105.04 $\mathrm{mg} \mathrm{L}^{-1}$, respectively. The maximum siderophore production $\left(22.23,19.34,10.12\right.$ and $\left.33.24 \mathrm{mg} \mathrm{mL}^{-1}\right)$ and

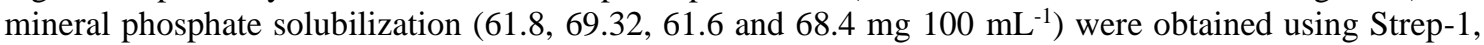
Strep-2, Strep-5 and Strep-8 isolates, respectively. None of the isolates could grow on nitrogen free media. The results of spinach root colonization test with the isolates indicated the potential of Strep-1, Strep-2, Strep-5 and Strep-8 isolates to colonize spinach roots.
\end{abstract}

Keywords: Actinobacteria, auxin, fertilizer, phosphate solubilization, siderophore

\section{Introduction}

In the recent decades, the negative impacts of chemical fertilizers on the environment have resulted in a search for new ways to increase productivity in the agricultural sector while decreasing the eradication of natural resources. One way to address this issue is taking advantage of the vast variety of beneficial microorganisms that are already present in soil and rhizosphere of plants. They can be applied as bio-fertilizers rather than using chemical fertilizers to promote plant growth (Chandini et al., 2019). Plant growth promoting rhizobacteria (PGPR) have various modes of actions such as altering plant hormones, secretion of organic compounds, increasing abiotic stress tolerance in plants, and enhancing nutrient availability and uptake (Wang et al., 2020). Based on the 
need for desirable PGP (plant growth promoting) traits, different rhizobacteria could be selected to be applied as bio-fertilizers. The most common desirable traits that we are looking for in PGPR include the production of auxin and siderophores, solubilization of phosphate and nitrogen fixation. Vast majorities of PGPR have been identified and exploited so far (Lamizadeh et al., 2016; Wang et al., 2020; Pourjasem et al., 2020). Actinomycetes comprise 10 to $50 \%$ of the soil microflora (Olanrewaju and Babalola, 2019) and produce a wide range of effective compounds. The researchers have documented them due to secondary metabolites produced as antifungal, insecticidal, antibacterial and anthelminthic compounds (Tyc et al., 2017).

Streptomyces is the largest genus of Actinobacteria in soil and widely recognized due to its ability to produce antibiotics and its biocontrol and pharmaceutical exploitation (Quinn et al., 2020; Newitt et al., 2019; Kumari et al., 2017; Franco-Correa et al., 2010). However, there has not been proper attention paid to the agricultural aspect of this genus, in regards to its use as biofertilizer and PGP traits, whereas there has been more focus on the biocontrol activity of this genus (Hamedi and Mohammadipanah, 2015; Adegboye and Babalola, 2012; Tyc et al., 2017).

Streptomyces effectively colonize the rhizoplane and rhizosphere. Due to their endophytic ability, they are capable of controlling gene expression and impacting the production of siderophores, phytohormones and some other traits (de Jesus Sousa and Olivares, 2016). Plant growth promoting traits by Streptomyces have been reported in various studies (Suarez-Moreno et al., 2019). Streptomyces have their own filaments which enable them to absorb nutrients easily in the soil and rhizosphere (Liu et al., 2019) and through degradation of biological polymer or dissolution of mineral compounds they can provide nutrients for plants (Khamna et al., 2009). High production of indole acetic acid (IAA) (136 mg/l) has been recorded for Streptomyces mhcr0816 (Ghosh et al., 2013) which was comparable to the reported values of standard strains Rhizobium sp. and Bacillus sp. with the amount of 142 and $55 \mathrm{mg} / \mathrm{l}$, respectively. Chouyia et al. (2020) reported Streptomyces roseocinereus as an isolate capable of solubilization of phosphate through secretion of malic acid. Also, production of secondary metabolite such as siderophore by Streptomyces griseus has been studied by Fiebig et al. (2018). Streptomyces, being useful for functions such as biocontrol, biofertilizers, and volatile compound secretion is an excellent candidate for investigation (Jones and Elliot, 2017). Therefore, finding a good PGP Streptomyces (PGPS) and choosing the best root colonizer is the ultimate goal. The aim of this study was to isolate Streptomyces from the rhizosphere of some different plants and trees at different locations of San Fernando Valley, Los Angeles, and to evaluate some PGP traits of the isolates. The second goal was to investigate the isolates' abilities to colonize spinach (Spinacia oleracea L.) roots, as spinach is a highly consumed vegetable with high nutritional values. The best PGPS strains will be considered as potential strains for future field study.

\section{Materials and methods}

\section{Isolation of Streptomyces from collected samples}

Soil samples were collected from 4 different locations of San Fernando Valley Los Angeles, California (Table 1). The soil samples were gathered from the rhizosphere along with the roots from fields of tomatoes, sunflowers and orange trees. The samples were transferred to the laboratory and kept in a refrigerator at $4{ }^{\circ} \mathrm{C}$ until the analysis started. 
Table 1. Coordination and location of sampling for each identified isolate as Streptomyces

\begin{tabular}{c|c|c|c|c}
\hline Isolate code & Plant's rhizosphere & Field location & Latitude & Longitude \\
\hline Strep-1 & Tomatoes & West Hills & $34^{\circ} 10^{\prime} 54^{\prime \prime} \mathrm{N}$ & $118^{\circ} 34^{\prime} 16^{\prime \prime} \mathrm{W}$ \\
Strep-2 & Tomatoes & San Fernando & $34^{\circ} 16^{\prime} 45^{\prime \prime} \mathrm{N}$ & $118^{\circ} 27^{\prime} 47^{\prime \prime} \mathrm{W}$ \\
Strep-3 & Cactus & Woodland Hills & $34^{\circ} 10^{\prime} 59^{\prime \prime} \mathrm{N}$ & $118^{\circ} 34^{\prime} 14^{\prime \prime} \mathrm{W}$ \\
Strep-4 & Nectarines & West Hills & $34^{\circ} 21^{\prime} 78^{\prime \prime} \mathrm{N}$ & $118^{\circ} 64^{\prime} 04^{\prime \prime} \mathrm{W}$ \\
Strep-5 & Sunflowers & San Fernando & $34^{\circ} 16^{\prime} 40^{\prime \prime} \mathrm{N}$ & $118^{\circ} 27^{\prime} 51^{\prime \prime} \mathrm{W}$ \\
Strep-6 & Lettuce & San Fernando & $34^{\circ} 16^{\prime} 56^{\prime \prime} \mathrm{N}$ & $118^{\circ} 27^{\prime} 38^{\prime \prime} \mathrm{W}$ \\
Strep-7 & Cactus & Woodland Hills & $34^{\circ} 10^{\prime} 51^{\prime \prime} \mathrm{N}$ & $118^{\circ} 34^{\prime} 20^{\prime \prime} \mathrm{W}$ \\
Strep-8 & Sunflowers & San Fernando & $34^{\circ} 16^{\prime} 42^{\prime \prime} \mathrm{N}$ & $118^{\circ} 27^{\prime} 49^{\prime \prime} \mathrm{W}$ \\
Strep-9 & Nectarines & West hills & $34^{\circ} 21^{\prime} 71^{\prime \prime} \mathrm{N}$ & $118^{\circ} 64^{\prime} 16^{\prime \prime} \mathrm{W}$ \\
Strep-10 & Lettuce & West hills & $34^{\circ} 21^{\prime} 61^{\prime \prime} \mathrm{N}$ & $118^{\circ} 64^{\prime} 25^{\prime \prime} \mathrm{W}$ \\
\hline
\end{tabular}

Serial dilutions of each sample up to $10^{-5}$ were made using one gram of soil. Then, $100 \mu \mathrm{l}$ of each dilution was spread evenly on plates containing ISP-2 (Yeast ExtractMalt Agar) medium supplemented with streptomycin to avoid the growth of unwanted microorganisms. After 7 days candidate colonies were streaked on ISP-2 media to achieve single colonies for further investigations (Priyadarshini et al., 2016). The carbohydrate utilization of purified Streptomyces candidates was determined by growth on carbon utilization medium (ISP-2), Tryptone yeast extract agar (ISP-1) and Starch casein agar (ISP-4). Gram staining and catalase tests were performed on the isolates.

\section{Plant growth promotion traits}

\section{Indole-3-acetic acid production}

The IAA production ability of the Streptomyces candidates was assessed using the colorimetric method (Bano and Musarrat, 2003). The isolates were grown in tryptone yeast extract broth medium containing $2 \mathrm{mg} \mathrm{mL}^{-1} \mathrm{~L}$-tryptophan and incubated at $29{ }^{\circ} \mathrm{C}$ under shaking at $125 \mathrm{rpm}$ for 7 days. Thereafter cells were collected by centrifugation of inoculum at $11,000 \mathrm{rpm}$ for $15 \mathrm{~min}$. Then $2 \mathrm{ml}$ of Salkowski reagent $(2 \mathrm{ml} 0.5 \mathrm{M}$ $\mathrm{FeCl}_{3}, 98 \mathrm{ml} \mathrm{35 \%} \mathrm{HClO}_{4}$ ) was added to one $\mathrm{mL}$ of the collected supernatant and mixed well. The amount of IAA production was calculated after reading the optical density at $535 \mathrm{~nm}$ by spectrophotometer (Laxco, Alpha1502. USA).

\section{Phosphate solubilization}

The qualitative and quantitative ability of the Streptomyces isolates to solubilize phosphate were investigated using methods of Pikovskaya (1948). A spot inoculation of different isolates of Streptomyces was applied on solid PVK medium in plates at 3 replications and the plates incubated at $29{ }^{\circ} \mathrm{C}$ for 7 days. The plates of $\mathrm{PKV}$ without inoculation were used as control.

Creation of clear halo around the colonies was indicated as phosphate solubilization capability of the isolates. For quantitative analysis of phosphate dissolution $2 \% \mathrm{v} / \mathrm{v}$ of 5 day old isolate $\left(10^{6} \mathrm{Cfu} \mathrm{mL}^{-1}\right)$ was inoculated in liquid PVK medium containing $1.5 \mathrm{~g} \mathrm{~L}^{-1}$ of $\mathrm{Ca}_{3}(\mathrm{PO} 4)_{2}$. After 5 days shaking-incubation of flasks at $28{ }^{\circ} \mathrm{C}$, inside suspensions were centrifuged to remove cells and debris. The phosphorous content of 
supernatants was determined by colorimetric method using an ammonium molybdate vanadate reagent and reading absorbance at $470 \mathrm{~nm}$ (Jeon et al., 2003) via spectrophotometer (Laxco, Alpha1502. USA).

\section{Siderophore production}

The Streptomyces candidates were evaluated for quantitative and qualitative siderophore production according to the method of Alexander and Zuberer (1991). The plates containing of Chrome Azurol S agar medium were prepared and inoculated with fresh 5-day culture $\left(10^{6} \mathrm{CFU} \mathrm{mL} \mathrm{m}^{-1}\right)$ of each isolate and incubated for 7 days at $29^{\circ} \mathrm{C}$. The orange and yellow halos around the colonies were considered as positive results for siderophore production test. A sidrophore production index was calculated using the ratio of total diameter of the colony plus the halo divided by colony diameter. The quantitative siderophore production was determined by inoculating ISP-2 broth media with 5-day old Streptomyces isolates and incubation the inoculated flasks at $29{ }^{\circ} \mathrm{C}$ under constant shaking condition $(120 \mathrm{rpm})$ for 5 days. Afterwards, suspensions were centrifuged (11,000 rpm for $14 \mathrm{~min})$ and the amount of produced siderophore was measured following assays of CAS-Shuttle (Milagres et al., 1999). In which $0.5 \mathrm{~mL}$ of supernatant was completely mixed with $0.5 \mathrm{~mL}$ CAS reagent then absorbance was read at $630 \mathrm{~nm}$ using a spectrophotometer (Laxco, Alpha1502. USA).

\section{Nitrogen fixation}

Nitrogen fixation ability of the isolates was determined using nitrogen free medium through acetylene reduction assay (ARA) and gas chromatography (Hardy et al., 1968).

\section{In-vitro spinach seed colonization test}

The ability of Streptomyces isolates to colonize spinach seeds was investigated by the described method of Bulgarelli et al. (2012). For this purpose, Spinach seeds, which were donated by Sakata Seeds America INC, were sterilized by submerging the seeds in $2 \%$ sodium hypochlorite solution for $5 \mathrm{~min}$ then the seeds were rinsed by sterile water up to six times. The tubes $(25 \times 150 \mathrm{~mm}$ diameter $)$ were filled with sterilized mixture of soil peat and sand (3:1) and a seed placed at depth of $2 \mathrm{~cm}$ of soil surface inside the tubes. The experiment was performed as completely randomized design at three replications including 4 isolates. Seedlings with root system were carefully removed from the tubes. About $1 \mathrm{~mL}$ of broth culture (5-day old) of each Streptomyces isolate with $10^{6} \mathrm{Cfu} \mathrm{mL}^{-1}$ was inoculated on seed. Tubes were kept in growth chamber at $25^{\circ} \mathrm{C}, 70 \%$ humidity and $12 \mathrm{~h}$ photo period for 20 days. In order to supply water, the tubes were irrigated with sterilized distilled water. The roots were separated from seedlings and gently washed by sterile water, then air-dried and weighed. The roots were cut and vortexed after soaking for $1 \mathrm{~h}$ in sterile solution of $0.9 \% \mathrm{NaCl}$. Serial dilutions of soaked roots were prepared and $100 \mu 1$ of suspension was cultured on ISP-4 solid media for colony counting. After 4 days the population of bacteria were enumerated and recorded as $\mathrm{CFU} \mathrm{g}^{-1}$ of root weight.

\section{PCR amplification and DNA sequencing}

Colony PCR (Hou et al., 2016) was applied for molecular identification of 4 selected Streptomyces isolates (having best plant growth promoting traits). Fresh cultures of each 
isolate were prepared by re-culturing isolates on Starch Casein Agar plates and incubating at $29^{\circ} \mathrm{C}$ for 4 days until the colonies reached a diameter of 2 to $3 \mathrm{~mm}$. Colonies were picked up from the plate using a sterile pipette tip and re-suspended in Master Mix (New England Bio labs, USA) solution. PCR amplification was performed using Master Mix and $0.4 \mu \mathrm{M}$ primer fD1 (5'-GAGTTTGATCCTGGCTCA-3') and Rp2 (5'-CGGCTACCTTGTTACGACTT-3') with final volume of $25 \mu \mathrm{l}$ in thermal cycler (MJ Research PTC-200, USA) with a program as: $94^{\circ} \mathrm{C}$ for $5 \mathrm{~min}$ as a primary denaturation step, 30 cycles of $94^{\circ} \mathrm{C}$ for $1 \mathrm{~min}, 57^{\circ} \mathrm{C}$ for $1 \mathrm{~min}, 72^{\circ} \mathrm{C}$ for $105 \mathrm{~s}$ and final extension of $72^{\circ} \mathrm{C}$ for $10 \mathrm{~min}$. The PCR products were closely visualized using gel electrophoresis on $0.8 \%$ agarose and compared with $1 \mathrm{~kb}$ DNA ladder (New England Bio labs, USA). The PCR products were purified using PCR purification kit (Monarch. USA) according to the manufacturer's instruction then were sequenced by MR DNA Molecular Research, (TX, USA). The products were sequenced and the results were compared with other sequences via BLAST software and the results deposited in NCBI GenBank as 16S rDNA gene of different Streptomyces species. Distance matrix was assessed using the Maximum Composite Likelihood approach based on the Kimura 2parameter model (Kimura, 1980) and phylogenetic tree was drawn using the MGA program (version 6) by bootstrap analysis of 1000 replications.

\section{Statistical analysis}

Analyses were done using SAS software, version 9.4. All comparison tests were based on completely randomized design with three replications, submitting to ANOVA and Tukey grouping was done for comparison means at a significant level of $\alpha=0.05$. Data for root colonization were log-transformed. The Pearson correlations between the $\mathrm{P}$ dissolution and siderophore production and $\mathrm{pH}$ of each medium were determined using SPSS 16.0 software.

\section{Results}

A total of 30 isolates from 6 different plants were isolated. However, 10 isolates with colony similarity to Streptomyces standard colony were selected for further analysis. Colonies appearance have been documented in Table 2, which were hard with chalky texture and wrinkly appearance (Fig. 1). They were gram positive and showed positive results to catalase test. All Streptomyces isolates were able to grow and utilize different source of carbon (Table 2).

Table 2. The colony color and some biochemical characteristic of isolates and accession number of identified isolates

\begin{tabular}{c|c|c|c|c|c}
\hline Isolate code & Colony color & Catalase & C-utilization & Accession number & Species \\
\hline Strep-1 & Yellow & + & + & MK483345 & Streptomyces griseus strain 52-1 \\
Strep-2 & Gray & + & + & MK483346 & Streptomyces albogriseolus strain DSM 4 \\
Strep-3 & Light brown & + & + & & \\
Strep-4 & Brown & + & + & MK483347 & Streptomyces aurantiacus strain 4683 \\
Strep-5 & Light yellow & + & + & & \\
Strep-6 & Light gray & + & + & & \\
Strep-7 & Orange & + & + & MK490964 & Streptomyces kanamyceticus strain 22-5 \\
Strep-8 & White & + & + & & \\
Strep-9 & Gray & + & + & & \\
Strep-10 & Yellow & + & + &
\end{tabular}




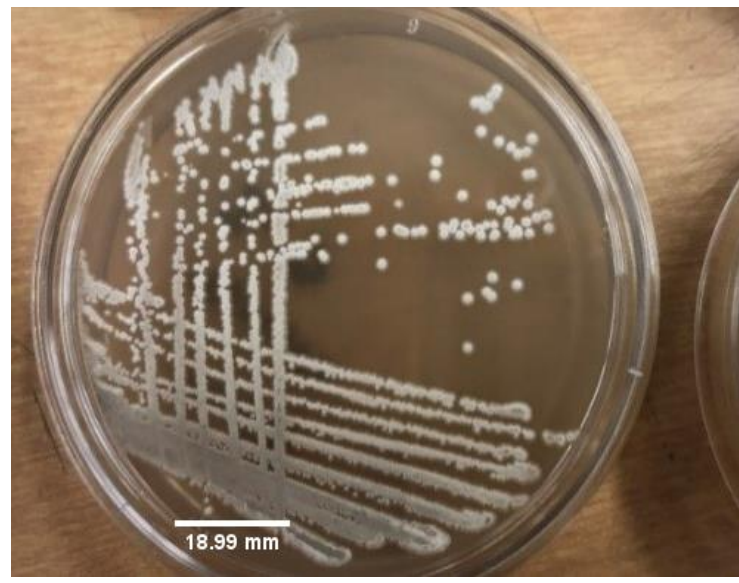

Figure 1. Colony morphology of the isolate Strep-2 on Casein yeast extract agar

All the Streptomyces isolates were able to produce IAA. Observing different intensity of pink color production by the candidates showed the presence of various amount of IAA (34.69 to $110.14 \mu \mathrm{g} \mathrm{mL}^{-1}$ ) (Table 3). Amount of IAA production by different Streptomyces candidates was significantly different by Tukey mean comparison $(\mathrm{p}<0.05)$. The maximum amount of auxin production belonged to the isolate of strep-2 which was from the tomato rhizosphere and the least amount belonged to Strep-7 from the cactus rhizosphere.

Table 3. Phosphate dissolution, siderophore production and $\mathrm{pH}$ of broth medium inoculated with rhizospheric Streptomyces isolates at in-vitro conditions.

\begin{tabular}{c|c|c|c|c|c|c|c}
\hline Isolate code & $\mathbf{S I}^{\mathbf{a}}$ & $\begin{array}{c}\mathbf{P} \\
\left(\mathbf{m g ~ 1 0 0} \mathbf{~ m L}^{-\mathbf{1}}\right)\end{array}$ & $\mathbf{p H}^{\mathrm{a}}$ & $\mathbf{S I}^{\mathbf{b}}$ & $\begin{array}{c}\text { Siderophore } \\
\left(\mathbf{m g ~ L} \mathbf{~ L}^{-\mathbf{1}}\right.\end{array}$ & $\mathbf{p H}^{\mathbf{b}}$ & $\begin{array}{c}\mathbf{I A A} \\
\left(\mathbf{m g ~ \mathbf { L } ^ { - 1 }}\right)\end{array}$ \\
\hline Strep-1 & $1.23 \pm 0.02$ & $61.8 \pm 0.43^{\mathrm{c}}$ & 5.5 & $1.99 \pm 0.02$ & $22.23 \pm 0.23^{\mathrm{b}}$ & 6.6 & $95.67 \pm 0.8^{\mathrm{c}}$ \\
Strep-2 & $1.82 \pm 0.04$ & $69.32 \pm 0.34^{\mathrm{a}}$ & 5.1 & $1.84 \pm 0.05$ & $19.34 \pm 0.34^{\mathrm{d}}$ & 6.7 & $110.14 \pm 0.9^{\mathrm{a}}$ \\
Strep-3 & $0.98 \pm 0.02$ & $41.53 \pm 1.2^{\mathrm{e}}$ & 5.5 & $1.13 \pm 0.03$ & $11.31 \pm 0.44^{\mathrm{h}}$ & 7.0 & $41.65 \pm 0.34^{\mathrm{g}}$ \\
Strep-4 & $1.61 \pm 0.03$ & $66.3 \pm 0.20^{\mathrm{b}}$ & 5.4 & $1.81 \pm 0.04$ & $20.3 \pm 0.16^{\mathrm{c}}$ & 6.6 & $40.04 \pm 0.25^{\mathrm{h}}$ \\
Strep-5 & $1.36 \pm 0.02$ & $61.6 \pm 0.33^{\mathrm{c}}$ & 5.4 & $1.16 \pm 0.02$ & $10.12 \pm 0.33^{\mathrm{i}}$ & 7.0 & $94.12 \pm 1.2^{\mathrm{d}}$ \\
Strep-6 & $1.27 \pm 0.03$ & $59.2 \pm 0.24^{\mathrm{d}}$ & 5.5 & $1.26 \pm 0.04$ & $16.45 \pm 0.19^{\mathrm{g}}$ & 6.9 & $63.93 \pm 1.3^{\mathrm{e}}$ \\
Strep-7 & $0.88 \pm 0.02$ & $39.23 \pm 0.65^{\mathrm{ef}}$ & 5.8 & $1.44 \pm 0.05$ & $17.98 \pm 0.45^{\mathrm{e}}$ & 6.9 & $34.67 \pm 0.87^{\mathrm{i}}$ \\
Strep-8 & $1.74 \pm 0.04$ & $68.40 \pm 0.33^{\mathrm{a}}$ & 5.3 & $2.14 \pm 0.06$ & $33.24 \pm 0.41^{\mathrm{a}}$ & 6.5 & $105.04 \pm 0.98^{\mathrm{b}}$ \\
Strep-9 & $0.78 \pm 0.04$ & $30.66 \pm 0.11^{\mathrm{g}}$ & 5.8 & $1.35 \pm 0.01$ & $17.01 \pm 0.23^{\mathrm{f}}$ & 6.8 & $41.01 \pm 0.87^{\mathrm{h}}$ \\
Strep-10 & $0.94 \pm 0.05$ & $40.87 \pm 0.43^{\mathrm{ef}}$ & 5.7 & $1.66 \pm 0.07$ & $18.56 \pm 0.46^{\mathrm{e}}$ & 6.8 & $52.64 \pm 1.32^{\mathrm{f}}$ \\
\hline
\end{tabular}

Data are means \pm standard deviation, $\mathrm{n}=3$. Columns with the same letter were not significantly different based on Tukey Multiple Test $(\alpha=0.05)$. SI, Solubilization index: (diameter of colony + halo zone)/colony diameter, ${ }^{\mathrm{a} \& \mathrm{~b}}$ the measured $\mathrm{SI}$ and $\mathrm{pH}$ of media related to the phosphate solubilisation and siderophore production tests, respectively

Among the isolates, six isolates having Solubilization Index (SI) greater than one were able to solubilize tri-calcium phosphate, as exhibited by the appearance of a clear halo around the colonies (Fig. 2). The highest calculated phosphate dissolution index of 1.82 was obtained by isolate Step-2. Quantitative analysis of phosphorus release to the broth medium indicated the maximum ability of isolate Step-2 to dissolve tri-calcium phosphate (Table 3). 


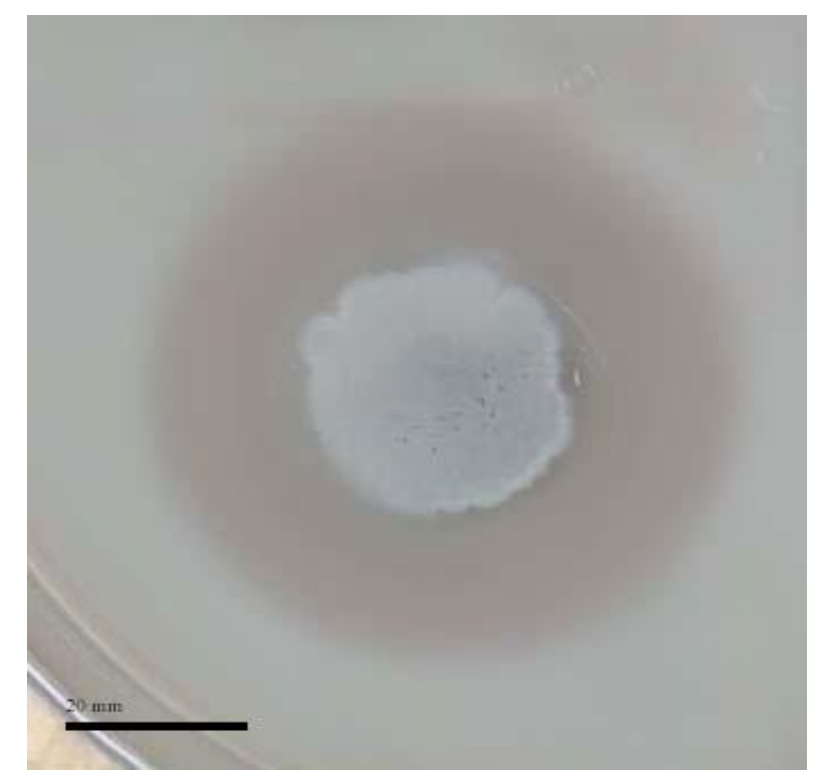

Figure 2. Halo around the bacterial colony indicates phosphate solubilization by isolate Strep2 on PVK medium with Phospahate Solubilization index (SI) of 1.82

There was not a significant difference between Strep-2 and Strep-8 by Tukey test, so both isolates were considered as high phosphate solubilizers. The $\mathrm{pH}$ of the culture medium of isolates changed from 6.0 to 5.1. The minimum $\mathrm{pH}$ belonged to the inoculated culture medium with the isolate Strep-2 (pH 5.1). There was a negative and significant correlation $\left(\mathrm{r}=-0.88^{* *}\right)$ between $\mathrm{pH}$ and $\mathrm{P}$ dissolution by isolates.

The isolates were able to produce siderophores, as exhibited by the creation of a yellow-orange halo around the colonies (Fig. 3). The maximum index of siderophore production of 2.1 was obtained by isolate Strep-8 from the sunflower's rhizosphere. The highest amount of siderophore production was $33.24 \mathrm{mg} \mathrm{mL}-1$ belonged to Strep-8 which was significantly different $(\mathrm{p}<0.05)$ among the isolates (Table 3). The highest siderophore content was measured at $\mathrm{pH} 6.5$ and the least content in $\mathrm{pH} 7.0$, but there was not significant correlation between $\mathrm{pH}$ of medium and siderophore content.

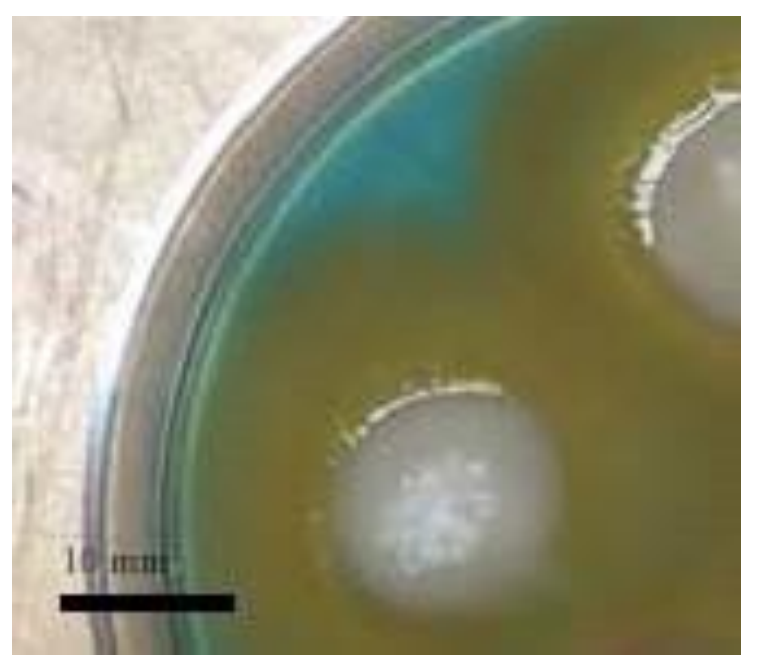

Figure 3. The yellow halo around the bacterial colony indicates siderophore production by isolate Strep-2 on CAS agar with Siderophore production index (SI) 1.84 
Streptomyces isolates were not able to grow on nitrogen free medium; therefore, the test did not indicate nitrogen fixing abilities in the isolates.

The ability to colonize spinach roots by Streptomyces varied among the isolates, with significant difference shown by Tukey's test (Fig. 4). The isolates of Strep-2, Strep-1 and Strep-8 from tomatoes and sunflower's rhizosphere indicated maximum root colonization with population numbers of $8.4 \times 10^{7}, 2.4 \times 10^{6}$ and $6.4 \times 10^{6} \mathrm{CFU} \mathrm{g}^{-1}$ fresh weight of root tissue, respectively. The least root colonization ability was shown by Strep-9 from the nectarine tree's rhizosphere with a population number of only $5.3 \times 10^{3}$ $\mathrm{CFU} \mathrm{g}^{-1}$ fresh weight of root tissue.

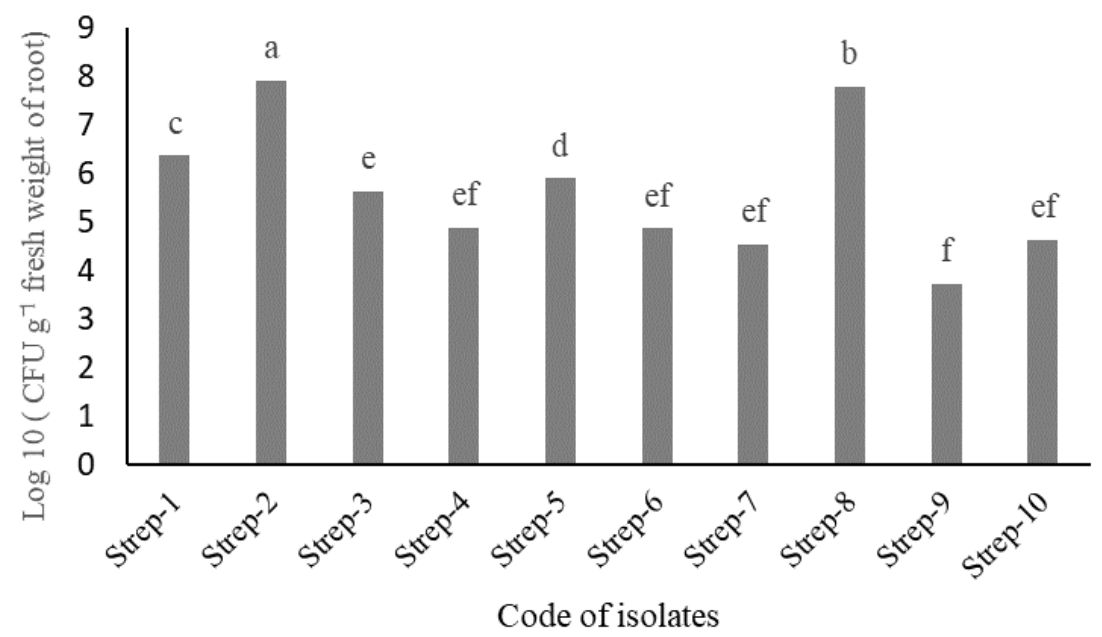

Figure 4. The population number of Streptomyces isolates in each treatment indicate the potential of isolates to colonize spinach root. Columns followed by the same letter are not significantly different according to the Tukey test at 5\% probability level $(n=3)$

The sequences of 16S rRNA gene of Strep-1, Strep-2, Strep-5 and Strep-8 isolates having the maximum PGP traits were analyzed through comparison with sequences in GenBank via Nucleotide BLAST on the NCBI website. After comparison, the isolates Strep-1, Strep-2, Strep-5 and Strep-8 showed similarity to Streptomyces griseus, Streptomyces albogriseolus, Streptomyces aurantiacus and Streptomyces kanamyceticus with accession number of MK483345, MK483346, MK483347 and MK490964, respectively (Table 2). The tree with the highest log likehood (-502.05) in Figure 5 indicated that isolates belonged to Streptomycetaceae.

\section{Discussion}

In this study, 10 Streptomyces isolates were identified from rhizospheric soil of different plants and trees. All of the isolates were investigated for some different plant growth promoting traits, and some of them represented better PGP traits under in-vitro conditions. The Streptomyces isolates were able to solubilize tri-calcium phosphate. This was probably by the lowering of $\mathrm{pH}$ through organic acid secretion or because of polysaccharide production (Elnahas et al., 2017). Chouyia et al. (2020) reported phosphate solubilization $\left(207.9 \mathrm{mg} \mathrm{L}^{-1}\right)$ by $S$. natalensis through decreasing $\mathrm{pH}$ in broth medium from 7 to 6. Similarly, Chaiharn, et al. (2018) reported $290.35 \mathrm{mg} \mathrm{L}^{-1}$ phosphate dissolution by Streptomyces isolates through decreasing $\mathrm{pH}$ from 7 to 4.5 in 
the media. Our observation indicated $\mathrm{pH}$ reduction in broth media after incubation from $\mathrm{pH} 6.9$ to 5.1 and 6.1 for different isolates. The isolates were able to produce IAA and siderophore which are the other two important factors for plant growth promotion. Siderophores are a low mass chelate made from peptides which form a complex of $\mathrm{Fe}^{3+}$ siderophore for plant uptake under iron deficiency conditions (Vessey, 2003). It has been reported that Streptomyces sp. GMKU3100, which is an endophytic bacterium, was capable of producing siderophores and promote the growth and yield of rice (Sadeghi et al., 2012). The amount of produced siderophore by the isolates varied among the Streptomyces isolates. Isolate Strep-8, which was from the sunflower's rhizosphere, created the biggest halo zone related to siderophore production, with $33.24 \mathrm{mg} \mathrm{L}^{-1}$ production in broth media. This is the same amount as Actinobacter strain mhcr0816 in the study of Elnahas et al. (2017). The reported siderophore and IAA production by $S$. roseocinereus MS1B15 (14.09 \pm 1.10 and $6.34 \pm 0.33 \mathrm{mg} / \mathrm{L})$, respectively were comparably lower than the measured amount of those by our studied strains (Suarez-Moreno et al., 2019). All studied isolates grown on tryptophan supplemented ISP-2 media, produced IAA in the range of 37 and $110.4 \mathrm{mg} \mathrm{L}^{-1}$. IAA is a high functional plant-growth hormone for increasing seed germination, hairy roots, root branching and elongation (Farina et al., 2012). Abd-Alla et al. (2013) and Myo et al. (2019) reported IAA production by Streptomyces sp. CMU-MH021 $\left(28.5 \mu \mathrm{g} \mathrm{mL}^{-1}\right)$ and Streptomyces fradia $\left(82.36 \mu \mathrm{g} \mathrm{mL} \mathrm{m}^{-1}\right)$. Results of the nitrogen fixation test revealed Streptomyces isolates were not able to grow on nitrogen free media. There were several reports which indicated disability of most Streptomyces species to fix molecular nitrogen except for Streptomyces thermoautotrophicus such that it is still controversial among some scientists to come to an agreement about the ability of this special species to fix nitrogen (Dahal et al., 2017; Zhao et al., 2006). It is a fact that roots of different crop varieties or species might produce different types of exudates, which could support and absorb different kinds of microorganisms with various plant growth promotion traits. Some proteins and chemical substances that are being secreted in the rhizosphere of different plants are crucial for root colonization by Streptomyces.

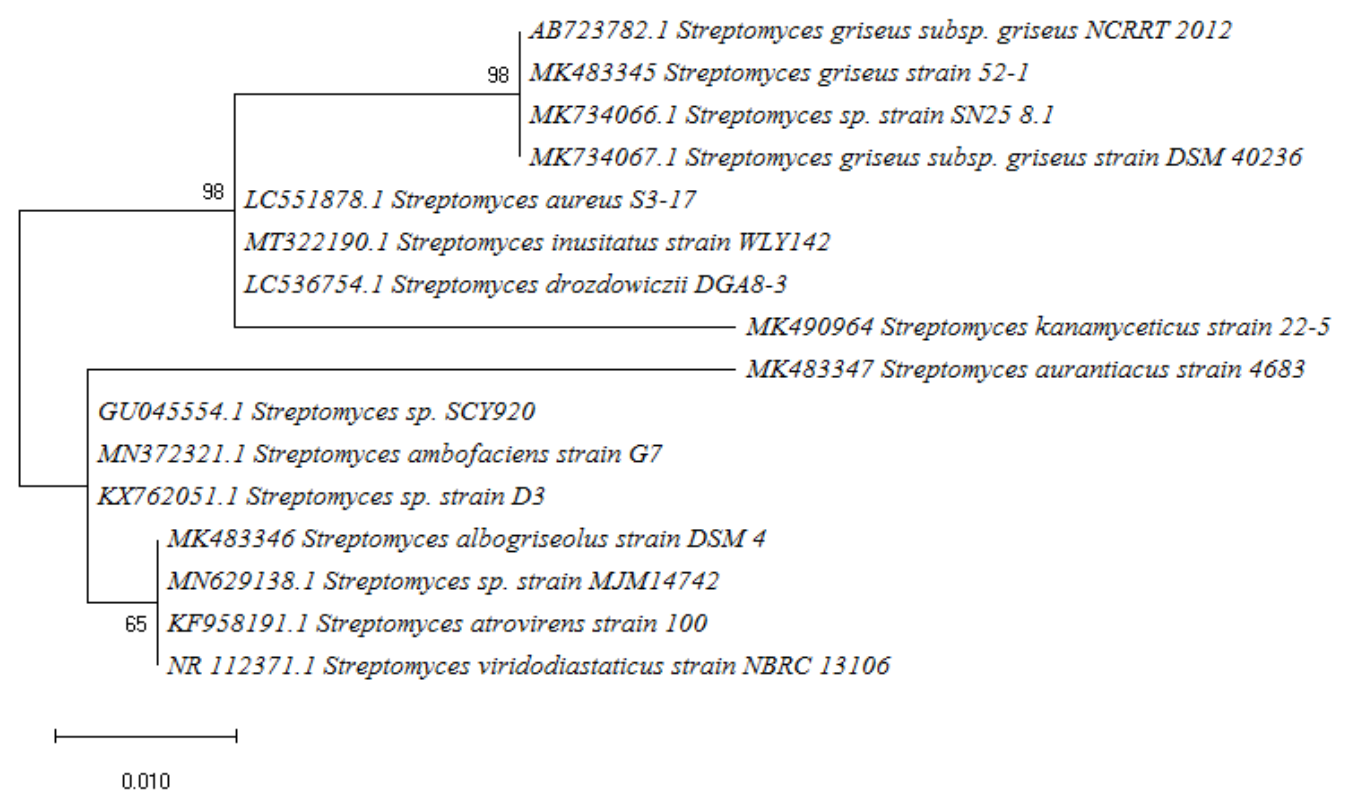

Figure 5. Phylogenetic tree of identified isolates based on 16S rRNA gene sequences. 
Kourenblum et al. (2020) reported the effect of rhizosphere and root exudates on the proportion of the microbial community close to the roots. Specific microbes thrive in the plant rhizosphere based on the chemical types of root exudates (Zhalnina et al., 2018). In vitro assessment of the Streptomyces isolates on spinach root colonization demonstrated the ability of these strains to colonize spinach roots with significant difference $(\mathrm{p}<0.05)$. In our study, the Streptomyces isolates from the cactus and nectarine rhizosphere showed lesser root colonization compared to the isolates from the tomato and sunflower rhizosphere, which shows the colonization might depend on the composition of root exudates. Acyl sugar metabolites have been represented as one of the main chemical root exudates in tomato root exudation, which correlated with Bacillales order (Kuorenblum et al., 2020). The higher root colonization by Streptomyces albogriseolus and Streptomyces kanamyceticus also with higher plant growth promoting traits from the rhizosphere of tomato and sunflower, may indicate the early influence of these isolates on spinach growth.

\section{Conclusion}

In sustainable agriculture, it is necessary to look for environmentally friendly ways to increase yield production without damaging the soil and water. Damage can result due to the application of different chemical fertilizers. Using bio-fertilizers as an alternative to chemical fertilizer should be investigated further in sustainable agriculture. Streptomyces, with all the evidence supporting its beneficial traits, can be considered as a bio-fertilizer. Up until now, it has been seldom applied as an inoculant to increase yield in agricultural products, despite the excellent potential shown in a vast number of scientific publications. We have found some beneficial Streptomyces strains with the ability to colonize spinach roots, and also with the ability of siderophore and IAA production, as well as phosphate dissolution from the San Fernando Valley, Los Angeles. These species are being maintained for future potential research in the field. The plant growth promotion and root colonization ability by strains $S$. albogriseolus and S. kanamyceticus suggest that these strains could be applied to plant growth promotion in spinach. More experiments are necessary to further verify the effects on spinach plants under natural growth conditions which is the goal of next study by the authors.

Acknowledgements. The authors appreciate the support of Deputy of Research and Technology of Agricultural Science and Natural Resources University of Khuzestan, Mollasani, Iran. Authors would like to Thank Agriculture and Life Science Departments of Pierce College for providing facilities and support. Thank you to Sakata Seeds. Special thanks to Karin Steinhauer and Amgen Biotech Experience.

Conflict of interests. The authors have declared no conflict of interests.

\section{REFERENCES}

[1] Abd-Alla, M. H., El-Sayed, E. S. A., Rasmey, A. H. M. (2013): Indole-3-acetic acid (IAA) production by Streptomyces atrovirens isolated from rhizospheric soil in Egypt. Journal of Biology and Earth Sciences 3: 182-193.

[2] Adegboye, M. F., Babalola, O. O. (2012): Taxonomy and ecology of antibiotic producing actinomycetes. - African Journal of Agricultural Research 7(15): 2255-2261.

[3] Alexander, D. B., Zuberer, D. A. (1991): Use of chrome azurol S reagents to evaluate siderophore production by rhizosphere. - Biology and Fertility of Soil 12: 39-45. 
[4] Bano, N., Musarrat, J. (2003): Characterization of a new Pseudomonas aeruginosa strain $\mathrm{Nj-15}$ as a potential biocontrol agent. - Current Microbiology 46: 324-328.

[5] Bulgarelli, D., Rott, M., Schlaeppi, M., van Themaat, E. V. L., Ahmadinejad, N., Assenza, F., Rauf, P., Huettel, B., Reinhardt, R., Schmelzer, E., Peplies, J. (2012): Revealing structure and assembly cues for Arabidopsis root-inhabiting bacterial microbiota. - Nature 488(7409): 91-95.

[6] Chaiharn, M., Pathom-Aree, W., Sujada, N., Lumyong, S. (2018): Characterization of phosphate solubilizing Streptomyces as a biofertilizer. - Chiang Mai Journal of Science 45(2): 701-716.

[7] Chandini, K. R., Kumar, R., Prakash, O. (2019): The impact of chemical fertilizers on our environment and ecosystem. - Research Trends in Environmental Sciences 69-86.

[8] Chouyia, F. E., Romano, I., Fechtali, T., Fagnano, M., Fiorentino, N., Visconti, D., Idbella, M., Ventorino, V., Pepe, O. (2020): P-solubilizing Streptomyces roseocinereus MS1B15 with multiple plant growth-promoting traits enhance barley development and regulate rhizosphere microbial population. - Frontiers in Plant Science 11: 1137.

[9] Dahal, B., Nandakafle, G., Perkins, L., Brozel, V. S. (2017): Diversity of free-living nitrogen fixing Streptomyces in soils of the badlands of South Dakota. - Microbiological Research 195: 31-39.

[10] de Jesus Sousa, J. A., Olivares, F. L. (2016): Plant growth promotion by Streptomycetes: ecophysiology, mechanisms and applications. - Chemical and Biological Technologies in Agriculture 3(1): 1-10.

[11] Elnahas, M. O., Amin, M. A., Hussein, M., Shanbhag, V. C., Ali, A. E., Wall, J. D. (2017): Isolation, Characterization and Bioactivities of an extracellular polysaccharide produced from Streptomyces sp.-MOE6. - Molecules 22(9): 1396.

[12] Farina, R., Beneduzi, A., Ambrosini, A., de Campos, S. B., Lisboa, B. B., Wendisch, V., Vargas, L. K., Passaglia, L. M. (2012): Diversity of plant growth promoting rhizobacteria communities associated with the stages of canola growth. - Applied Soil Ecology 55: 4452.

[13] Fiebig, D., Storka, J., Roeder, M., Meyners, C., Schmelz, S. S., Blankenfeldt, W., Scrima, A., Kolmar, H., Fuchsbauer, H. L. (2018): Destructive twisting of neutral metalloproteases: the catalysis mechanism of the Dispase autolysis-inducing protein from Streptomyces mobaraensis DSM 40487. - FEBS Journal 285(22): 4246-4264.

[14] Franco-Correa, M., Quintana, A., Duque, C., Barea, J. M. (2010): Evaluation of actinomycete strains for key traits related with plant growth-promotion and mycorrhiza helping activities. - Applied Soil Ecology 45: 209-217.

[15] Ghosh, P. K., Saha, P., Mayilraj, S., Maiti, T. K. (2013): Role of IAA metabolizing enzymes on production of IAA in root nodule of Cajanus cajanand its PGP Rhizobium sp. - Biocatalysis and Agricultural Biotechnology 2: 234-239.

[16] Hamedi, J., Mohammadipanah, F. (2015): Biotechnological application and taxonomical distribution of plant growth promoting actinobacteria. - Journal of Industrial Microbiology and Biotechnology 42(2): 157-171.

[17] Hardy, R. W. F., Holsten, R. D., Jackson, E. K., Burns, R. C. (1968): The acetyleneethylene assay for N2 fixation: laboratory and field evaluation. - Plant Physiology 43: 1185-1207.

[18] Hou, L., Zhang, X., Li, Y., Chen, S. H., Qu, H., Yu, J., Zhang, L., Fan, Z. (2016): Rapid screening of recombinant plasmids by direct colony quantitative real-time PCR. Advances in Bioscience and Biotechnology 7: 428-433.

[19] Jeon, J. S., Lee, S., Kim, H. Y., Ahn, T. S., Song, H. (2003): Plant growth promotion in soil by some inoculated microorganisms. - Journal of Microbiology 41: 271-276.

[20] Jones, S. E., Elliot, M. A. (2017): Streptomyces exploration: competition, volatile communication and new bacterial behaviours. - Trends in Microbiology 25(7): 522-531. 
[21] Khamna, S., Yokota, A., Lumyong, S. (2009): Actinomycetes isolated from medicinal plant rhizosphere soils: diversity and screening of antifungal compounds, indole-3-acetic acid and siderophore production. - World Journal of Microbiology and Biotechnology 25: 649-655.

[22] Kimura, M. (1980): A simple method for estimating evolutionary rate of base substitutions through comparative studies of nucleotide sequences. - Journal of Molecular Evolution 16: 111-120.

[23] Kourenblum, E., Dong, Y., Szymanski, J., Panda, S., Jozwiak, A., Massalha, H., Meir, S., Rogachev, I., Aharoni, A. (2020): Rhizosphere microbiome mediates systemic root metabolite exudation by root-to-root signaling. - Proceedings of the National Academy of Sciences 117: 3874-3883.

[24] Kumari, K. S., Kalyani, P., Vineela, K. C., Hemalatha, V., Hemalatha, K. P. G. (2017): Isolation of antibiotic producing actinomycetes from untapped soils of Yarada hills and assessment of their antimicrobial activities. - International Journal of Engineering Research \& Technology 3(2): 290-293.

[25] Lamizadeh, E., Enayatizamir, N., Motamedi, H. (2016): Isolation and identification of plant growth-promoting rhizobacteria (PGPR) from the rhizosphere of sugarcane in saline and non-saline soil. - International Journal of Current Microbiology \& Applied Science 5(10): 1072-1083.

[26] Liu, D., Yan, R., Fu, Y., Wang, X., Zhang, J., Xiang, W (2019): Antifungal, plant growth-promoting and genomic properties of an endophytic actinobacterium Streptomyces sp. NEAU-S7GS2. - Frontiers in Microbiology 10: 2077.

[27] Milagres, A. M., Machuca, A., Napoleao, D. (1999): Detection of siderophore production from several fungi and bacteria by a modification of chrome azurol S (CAS) agar plate assay. - Journal of Microbiological Methods 37(1): 1-6.

[28] Myo, E. M., Ge, B., Ma, J., Cui, H., Liu, B., Shi, L., Jiang, M. (2019): Indole-3-acetic acid production by Streptomyces fradiae NKZ-259 and its formulation to enhance plant growth. - BMC Microbiology 19(1): 1-14.

[29] Newitt, J. T., Prudence, S. M., Hutchings, M. I., Worsley, S. F. (2019): Biocontrol of cereal crop diseases using Streptomycetes. - Pathogens 8(2): 78.

[30] Olanrewaju, O. S., Babalola, O. O. (2019): Streptomyces: implications and interactions in plant growth promotion. - Applied Microbiology and Biotechnology 103(3): 1179-1188.

[31] Pikovskaya, R. I. (1948): Mobilization of phosphorus in soil in connection with the vital activity of some microbial species. - Microbioligia 17: 362-370.

[32] Pourjasem, L., Landi, A., Enayatizamir, N., Hojati, S. (2020): The release of some elements from vermiculite during the short periods of incubation by heterotrophic bacteria. - Eurasian Soil Science 53(2): 223-229.

[33] Priyadarshini, A., Singdevsachan, S. K., Tripathy, S. K., Mohanta, Y. K., Patra, J. K., Sethi, B. K. (2016): Isolation and identification of Actinomycetes from Mangrove soil and extraction of secondary metabolites for antibacterial activity. - Biotechnology Journal International 12(2).

[34] Quinn, G. A., Banat, A. M., Abdelhameed, A. M., Banat, I. M. (2020): Streptomyces from traditional medicine: sources of new innovations in antibiotic discovery. - Journal of Medical Microbiology 69(8): 1040.

[35] Sadeghi, A., Karimi, E., Dahaji, P. A., Javid, M. G., Dalvand, Y., Askari, H. (2012): Plant growth promoting activity of an auxin and siderophore producing isolate of Streptomyces under saline soil conditions. - World Journal of Microbiology and Biotechnology 28(4): 1503-1509.

[36] Suarez-Moreno, Z. R., Vinchira-Villarraga, D. M., Vergara-Morales, D. I., Castellanos, L., Ramos, F. A., Guarnaccia, C., Degrassi, G., Venturi, V., Moreno-Sarmiento, N. (2019): Plant-growth promotion and biocontrol properties of three Streptomyces spp. isolates to control bacterial rice pathogens. - Frontiers in Microbiology 10: 290. 
[37] Tyc, O., Song, C., Dickschat, J. S., Vos, M., Garbeva, P. (2017): The ecological role of volatile and soluble secondary metabolites produced by soil bacteria. - Trends in Microbiology 25(4): 280-292.

[38] Vessey, J. K. (2003): Plant growth promoting rhizobacteria as bio fertilizers. - Plant and Soil 255: 571-586.

[39] Wang, J., Li, R., Zhang, H., Wei, G., Li, Z. (2020): Beneficial bacteria activate nutrients and promote wheat growth under conditions of reduced fertilizer application. - BMC Microbiology 20: 1-12.

[40] Zhalnina, K., Louie, K. B., Hao, Z., Mansoori, N., da Rocha, U. N., Shi, S., Cho, H., Karaoz, U., Loque, D., Bowen, B. P., Firestone, M. K. (2018): Dynamic root exudate chemistry and microbial substrate preferences drive patterns in rhizosphere microbial community assembly. - Nature Microbiology 3(4): 470-480.

[41] Zhao, Y., Bian, S. M., Zhou, H. N., Huang, J. F. (2006): Diversity of nitrogenase systems in diazotrophs. - Journal of Integrative of Plant Biology 48(7): 745-755. 